\title{
From one word to two words: repetition patterns on the way to structured speech*
}

\author{
EDY VENEZIANO, HERMINE SINCLAIR \\ AND IOANNA BERTHOUD \\ Université de Genève
}

(Received 28 fuly 1988. Revised 2 August 1989)

\section{A BSTRACT}

This paper gives an account of the transition from one-word to multiword utterances based on the productions of one child from age $1 ; 5.23$ to $1 ; 8.15$ in spontaneous interaction with her mother. The authors' interpretation of the observed development emphasizes: (1) the initial dissociation and later co-ordination of temporal chaining of elements on the one hand and meaning-relatedness between elements on the other; and (2) the psychological importance of repetition patterns for the change from single-word functioning to meaning-related and temporally-chained multi-word utterances, i.e. utterances that show the duality of patterning characteristic of human language.

Since the sixties when several authors (among others Braine, I963, I976; Miller \& Ervin, 1964; Bloom, 1970; Brown, 1973; Schlesinger, 1974) published important work on the beginnings of 'combinatorial' or 'patterned' speech, some further publications (Bloom, I973; Scollon, 1974; Dore, Franklin, Miller \& Ramer, I 976; Greenfield \& Smith, 1976) have been directly concerned with the period during which the child gives evidence of what Dore et al. (1 976) called 'something more than one word and something less than syntax'. Since there is as yet no theoretically motivated description of the beginnings of grammar in young children, let alone an explanation, this period merits close attention. The preliminary analysis of a corpus of videotaped longitudinal observations of eight French-speaking mother-child dyads showed the existence of essentially the same transitional phenomena already noted by Bloom (1973), Dore et al. (1976), Scollon (1974, 1979) and

[*] This research was supported by a grant from the Fonds National suisse de la Recherche Scientifique (FNRS) (No. 1. 168-0.85) to Hermine Sinclair and Ioanna Berthoud. We wish to express our thanks to the parents and children who participated in this study. Address for correspondence Edy Veneziano, F.P.S.E., Université de Genève, 1211 Genève 4, Switzerland. 
others, but a detailed analysis of the appearance and changing proportional occurrence of these phenomena led us to propose a partially novel view of the development that leads to the so-called 'patterned speech' of the first twoword utterances, and to its possible importance for further acquisitions. Following a suggestion by Atkinson ( 1985 ), we turned to a reconsideration of one of the so-called 'design features' of human language (Hockett, I 958, but earlier Martinet, I 949 and de Saussure, I9 16; cf. also Lyons, 1977).

Discreteness, arbitrariness and conventionality, semanticity and interchangeability of linguistic systems can already be considered present during the child's one-word period and will not be discussed in this paper. The design feature discussed in this paper is that of duality of patterning, often seen as the most essential property of human language and, by definition, absent from single-word speech. It is useful to remember that de Saussure, who did not explicitly refer to the two structural levels, i.e. phonological and morphosyntactic, was the first to point to the necessary linearity of language: the units of the system cannot but follow the irreversible flow of time; it is never possible for two units to be present simultaneously. Obviously this temporal chaining of elements is implied in duality of patterning and constitutes its first aspect, but duality of patterning also implies, first, that the chained elements stand in some kind of meaning relation to one another and, secondly, that the chaining of meaning-related words is, in general, subject to structural rules.

We propose that the different aspects of duality of patterning do not appear simultaneously in the speech of young children, but that the beginnings of grammar ('structural rules') depend on a coordination of the first two, i.e. CHAINING and RELATING, which are elaborated in a partly separate way during the period of transition. Earlier work (notably by Bloom, I973, and by Dore et al., 1976: 26) suggested that two-word utterances grow out of the integration of previously acquired 'parts', i.e. prosodic patterns and conceptual relations. Our view differs as to the nature of the acquisitions to be coordinated. We think that the main acquisitions that lead to multiple-word speech are the ability to ExPREss with two words already established conceptual relations on the one hand, and the ability to utter words in temporal contiguity (not necessarily within a unique intonational contour) on the other. Our aim, like that of other researchers, is to see how transitional phenomena lead to multi-word speech but our aim is also to see whether these phenomena grow out of the child's functioning as a single-word speaker, which would suggest more than a descriptive continuity between one-word and two-word speech.

We are not in a position to discuss the linguistic status of the first two-word combinations, though we believe that, in general, they do not yet show evidence of grammar. But we do wish to emphasize that we consider the elaboration of CHAINING and RELATING as the acquisition of language-specific capacities and therefore linguistic in the broad sense. 


\section{METHOD}

The data reported below are part of a longitudinal study of eight motherchild dyads videotaped and audiorecorded in their homes during spontaneous interaction (some toys and two picture books were brought in and often used) for approximately one-hour sessions every two weeks. Systematic observations started once the children produced some ro single-word utterances and was terminated when at least is two-word utterances were recorded during one session. A case study of one child (second-born female of middleclass parents) was completed and a detailed analysis of four sessions Camille at $1 ; 5.23,1 ; 6.22,1 ; 7.18$ and $1 ; 8.15-$ is presented. (The sessions will be referred to as $C_{1} ; 5.23, C_{1} ; 6.22, C_{1} ; 7.18$, and $\left.C_{1} ; 8.15.\right)$ Transcripts of these sessions were made from the videotapes and were complemented by the audiorecords. Transcripts include information about pauses intervening between uninterrupted vocal sequences produced by the child and by the mother. Measurements were taken with the aid of a manual quartz stopwatch; repeated measures indicate the possibility of error of $\pm 10 \%$. Transcriptions were first done by one of us and checked by a second transcriber. The few cases of disagreement were in general resolved by repeated viewing of the tapes.

\section{Criteria of analysis}

Apart from the fact that prosodic (or intonational) patterns appear not to operate in the same way in French as in English, we consider that Branigan (1979) gave substantial evidence for his claim that successive single-word utterances do not differ from multi-word utterances with a unique intonational contour except in degree of completeness of the articulatory plan and in the fact that the latter are 'executed with temporal fluency' (p. $42 \mathrm{I}$ ) while the former are not. Consequently, we defined a 'single-utterance event' as a vocal sequence uninterrupted by the intervention of another speaker, provided that the elements of the sequence are not separated by a pause longer than two seconds. Whenever a single-utterance event (referred to as a turn) comprises more than one element, it constitutes an example of CHAINING whether there appeared to be a single intonational contour or not.

The question of the meaning-relatedness of two words can, it seems, never be decided without a context-based interpretation of the child's utterances. This problem is also faced by those who take the intonational contour as a criterion for a single-utterance event, and its daunting difficulties are all too apparent in the literature. In this respect we applied intuitive criteria similar to those utilized by most other researchers, using cues from the non-verbal context and from the dialogue. More specifically, relatedness is considered to be present when two or more words refer to a minimal event and/or communicative intention which the child seems to have in mind at the time 
of verbalization or which grows out of conversation between child and adult. We will refer to the latter as the child's 'intention'. The analysis of 'intentions' is based on ongoing activities, on activities occurring just before and just after a verbalization as well as on information from the dialogue. The following examples may clarify where we have placed the boundaries of an 'intention':

Example I from $\mathrm{C}_{1} ; 7.18$ ( $C$ indicating child)
C: dódó ${ }^{1}$
baby-talk for 'sleep'
C: la
(putting a baby doll in a toy cradle)
(completing the action)
'there'"2

In this example the two words express the same intention of putting the baby doll in the toy cradle.

Example 2 from $\mathrm{C}_{1} ; 5.23$

C: dódó

C: py

'no more' or

'allgone' (searching in a bag for a baby doll that she wants to put into a toy cradle - she had just putanother baby doll into a toy cradle) (not finding the baby in the bag - after the verbalization, she stands up and looks around on the floor)

In this example the two verbalizations belong to two different intentions since at the time of the first verbalization the child seems to have in mind putting the baby doll into the cradle while with her second verbalization she expresses the discovery that there are no more dolls in the bag (and not that she has finished putting baby dolls to sleep as one might conclude had she not continued her search).

Example 3 from $\mathrm{C}_{\mathrm{I}} ; 6.22$ ( $A$ indicating $A$ dult)
C: Japó
(taking a doll's hat)
'hat'
A: c'est pour qui
le chapeau?
(the child picks up the doll)
'whom is the hat for?'
C: pe
'poupée' = 'doll'

(starts to put the hat on the doll's head)

[1] Accents indicate stressed syllables.

[2] Translations of the child's utterances are literal translations. No attempt has been made to render what an English-acquiring child might have said.

$$
636
$$


The dialogue links the two words uttered by the child although here it is not clear whether it was the child herself who intended to put the hat on the doll's head.

The child's utterances were analysed by a first judge as to whether they belonged to the same or to different 'intentions'. $25 \%$ of the total number of child's turns of each session were submitted to a second judge who was familiarized with our criteria. The comparison yielded $93 \%$ agreement (mean over sessions).

\section{ANALYSIS AND RESULTS}

According to our definition, relatedness implies the production of more than one word to express different aspects of one intention. Some of children's functioning as single-word speakers (i.e. when they still produce one word to express a given intention) can be considered to prefigure and prepare for this ability.

One of the phenomena relevant here, reported also by other authors in different theoretical perspectives (particularly by Antinucci \& Parisi, I 973; Bloom, 1973; Greenfield \& Smith, 1976), is the following: children utter one word to express a particular intention; then, at a later time, when they express a very similar, seemingly identical, intention, they use a word different from the one they had used previously. The recurring intentions can occur close to each other in time (as in the examples below) or can be separated by a longer time interval. For example, at 1;5.23 Camille seven times repeats an action sequence in which she first climbs on a trunk and then jumps down aided by her mother. The first time, before climbing up, she says ão:o ão: $o^{3}$ ('en haut' = 'up'), the second and third time she says ko ('encore' = 'again'), the fourth time she says so:o ('saute' = 'jump') and the last three times she says again ko. In another instance, the child wants to make a mechanical frog work; when the frog stops moving she turns to the adult to make it work again. This situation recurs three times within a short period. To make the request she says once ga ('grenouille = 'frog'), once $t a$ ('tiens' = 'there') and another time ko ('encore' = 'again').

We think that the fact that the child can utter one or another word to express a recurring intention renders the different words likely candidates for eventually being uttered for one single intention.

Two other types of behaviour concern more specifically the object of our analysis here, namely, the child's verbalizations within one given intention, whether this is one of a set of recurring intentions - as those discussed above

[3] The : represents lengthening of the preceding vocalic sound. A vowel is transcribed a second time if the child articulates it again after lengthening. 
- or not. These are two types of repetition that we will call vertical and HORIZONTAL repetition.

(ia) Vertical Repetition (by extension of the term introduced by Scollon, 1974). The child produces one word to express a given intention; then, in her immediately following turn (often after a turn of the mother), she repeats the word to continue expressing the same intention:

\section{Example 4 from $\mathrm{C}_{1} ; 5.23$ ( $M$ indicating mother)}

C: bébé 'baby'

(puts the baby doll into a toy cradle)

M: oui le bébé fait dódó 'yes, the baby is asleep'

C: bébé

(holds baby doll in toy cradle)

'baby'

Example 5 from $\mathrm{C}_{\mathrm{I}} ; 5.23$

C: ka 'canard' = 'duck'

$\mathrm{M}$ : hein?

C: ka 'canard' = 'duck'

M: un canard? 'a duck?'

Example 6 from $\mathrm{C}_{\mathrm{I}} ; 5.23$

$\mathrm{C}$ : dódó

$\mathrm{M}$ : $\mathrm{mhmh}$

C: dódó

(puts baby-doll into toy cradle)

(keeps baby inside the toy cradle)

As can be seen from Examples 4-6, the reasons motivating the child to repeat her first verbalization are varied (conversational, communicative, lack of immediate accomplishment of the intended result). This phenomenon of vertical repetition, considered important for the establishment of the first shared elements (Veneziano, I 988 ), has not, to our knowledge, been treated within the context of the transition between single and multi-word speech. In our opinion, its importance resides in the fact that by repeating the originally uttered word, the child utters more than one word (although it is the same word repeated) to express one and the same intention.

(ib) HORIZONTAL REPETITION (again by extension of Scollon's terminology). The child produces a word and repeats it in close temporal contiguity within the same turn. For example, Camille says $k u: u . k u: u^{4}$ ('encore' = 'again')

[4] The point "." indicates the presence of a pause $(\leqslant 2 \mathrm{sec})$ between the vocal elements. 
looking at a mechanical frog that has just stopped moving and says $k i . k i$ ('musique' = 'music') going towards a taperecorder.

As in vertical repetition, in horizontal repetition the child produces more than one word to express one and the same intention, but here, the identical words are produced one after the other in temporal contiguity. Chaining and relating here find their most primitive realization prefiguring later developments.

Sometimes an intention finds expression through a combination of horizontal and vertical repetition as in the following example:

Example 7 from $1 ; 5.23$

$\mathrm{C}: \mathrm{ku} \cdot \mathrm{ku}$

'encore' = 'again'

(looking at mechanical toy that has just stopped working)

$\mathrm{M}$ : encore? tu veux encore? ( $C$ looks at $M$ who winds up toy) 'again? you want again?'

C: kor 'encore' = 'again'

Repetition seems to constitute an important connection between singleword and multi-word speech. When repetition bears on the child's singleword functioning it allows the production of more than one word for one given intention thereby creating the first relation between words, that of identity and, in the case of horizontal repetition, a chained utterance as well.

The two types of behaviour discussed next are transitional in the proper sense since the child either utters at least two different vocal elements in close temporal contiguity but with no unity of intention, or two different words to express one and the same intention, but in different turns.

(2) Chaining without relatedness. The child produces at least two elements in close temporal contiguity but either one of them is not clearly identifiable as a particular word or, if both are, then they are not related to one single intention:

Example 8 from $\mathrm{C}_{\mathrm{I}} ; \mathbf{5 . 2 3}$ - her mother has just told Camille that she has to put on her slippers before she can go on playing-Camille goes to her mother

$\mathrm{C}$ : tátú mamã mamã mam ([I] climbing on mother's knees;
[1] [2] [3]
'pantoufles' =
'slippers'
[4] [2-4] reaching for her bottle of juice standing on the table just beside her)

Whereas tátu refers to the slippers, the verbalization of the immediately following elements (mamã mamã mam) uttered while the child reaches for her bottle of juice, refers to her wanting the bottle. 
(3) Relatedness without chaining. The child utters two different words referring to a single intention on a given occasion, at one given moment; however, the words are uttered in different turns. This behaviour is similar to Bloom's 'holistic successive single word utterances' (1973), to Scollon's 'vertical constructions' (1974), and to Ochs, Schieffelin \& Platt's 'propositions across utterances' (1979) but it differs from them mainly because of our definition of chaining. Thus two words uttered in close temporal contiguity, though lacking a unique intonational contour, have not been included in this category.

The conversational functioning that gives rise to this phenomenon may simply be based on imitative replies:

Example 9 from $\mathrm{C}_{1} ; 6.22$-Camille is sitting on toy train; her mother has stopped pushing the train

C: ko

(looking at her mother)

'encore' = 'again'

M: encore un petit tour?

'again a little ride?'

C: tu

'tour' $=$ 'ride'

In other cases the conversational functioning is more mature. The child may utter the second word by replying to a well-chosen adult question or after the adult has shown that s/he shares the child's attention (for further examples of this type, see also Atkinson, 1979; Scollon, 1979):

Example 10 from $\mathrm{C}_{\mathrm{I}} ; 7.18$-Camille and her mother look at a picturebook C: $\quad$ e $\tilde{\boldsymbol{\varepsilon}}$

'le chien' = 'the dog'

$\mathrm{M}$ : le chien

'the dog'

$\mathrm{C}: \mathrm{ku}(\mathrm{r})$

'court' = 'run'

M: oui, il court le chien

'yes, he runs the dog'

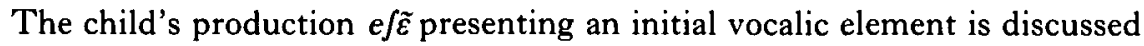
among other examples of this type towards the end of this section.

(4) The co-ordination of chaining and relatedness accompanied by repetition. The two words used to verbalize one given intention are uttered one after the other in close temporal contiguity and one of the elements is repeated. Two patterns have been observed: 
(a) The child utters a first word and then, either in the following turn or within the same turn, repeats this word before uttering the second one:

Example $1 \mathrm{I}$ from $\mathrm{C}_{\mathrm{I}} ; 6.22$
C: pié
(trying to fit a shoe to a doll)
C: piè. pié bébé
(continues the same action)
'foot. foot baby'

The child's verbalization takes the form $a / a b$.

(b) The child produces a first word; then, either in the following turn or in the same one, she utters a second word and, immediately afterwards, she repeats the first one.

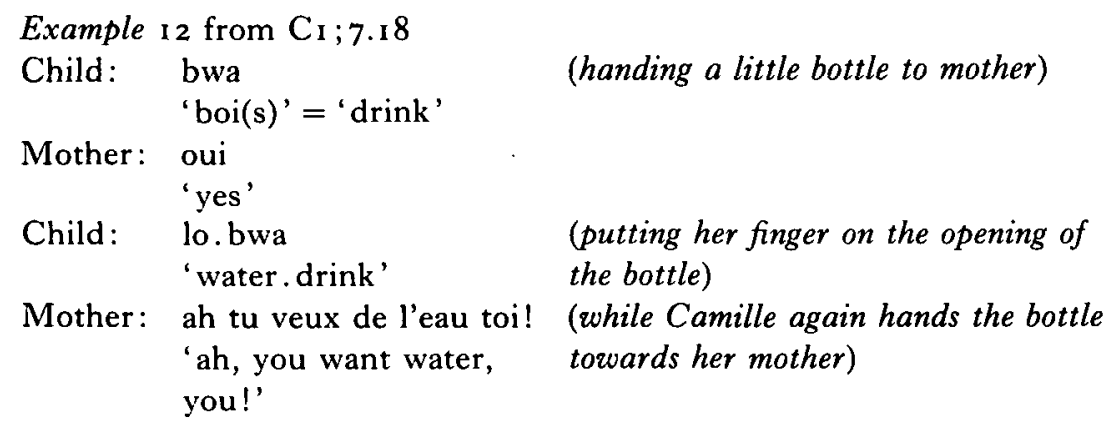

In this exchange the child's verbalization takes the form $a / b a$. From the point of view of the observer, the $a / b a$ pattern indicates the beginning of relatedness between the words contained in the utterance and not simply between the words and the intended situation. When the child expresses a single intention, why would she repeat a word (which she has already uttered on its own) closely after the production of another word unless the two chained words were somehow linked in her mind?

(5) The co-ordination of chaining and relatedness without repetition. The two related words are uttered one after the other without repetition of one of the elements. In some cases the two words are uttered within a single intonational contour. For example, at I ; 8. I 5 ; $\varepsilon v y$ ená ('seen Nutragenal' - Nutragenal is a cream), iá agy ('là' = 'there', 'gru' = 'crane'), oli oppón ('read Popol'). In other cases the two words are still separated by a pause: iá. aló ('là bouchon' $=$ 'there cork'), afã.obbé ('child fall').

All the categories discussed under ( 1 ) $-(5)$ lend themselves to quantification. Table I presents general data concerning the total number of turns analysed at each session, as well as the number of intentions and turns in categories (I) $-(5)$. The last row presents the mean number of turns per intention. 
TABLE I. Turns and intentions expressed through categories $(I)-(5)$, at each session

\begin{tabular}{lcccc}
\hline & \multicolumn{4}{c}{ Session and age } \\
& $\mathrm{C}_{1}-1 ; 5.23$ & $\mathrm{C}_{2}-1 ; 6.22$ & $\mathrm{C}_{3}-1 ; 7.18$ & $\mathrm{C}_{4}-1 ; 8.15$ \\
\hline $\begin{array}{l}\text { Total number of turns } \\
\text { Turns in categories (1)-(5) }\end{array}$ & 187 & 228 & 117 & 155 \\
$\quad$ & 100 & 117 & 67 & 99 \\
$\quad \begin{array}{l}\text { Number } \\
\quad \text { of Total }\end{array}$ & 53 & 51 & 57 & 64 \\
$\begin{array}{l}\text { No. of intentions } \\
\text { expressed through } \\
\text { categories (1)-(5) }\end{array}$ & 48 & 61 & 35 & 69 \\
$\begin{array}{l}\text { Mean number of turns } \\
\text { per intention }\end{array}$ & 2.08 & 1.92 & 1.91 & 1.43 \\
\hline
\end{tabular}

a Excluding turns containing ' $\mathrm{mh}$ ', 'hein' of confirmation or clarification and productions consisting only of a vowel.

At every session, over $50 \%$ of the turns belong to categories ( 1$)-(5)$. This proportion tends to increase at $\mathrm{C}_{1 ; 7.18}$ and $\mathrm{C}_{1} ; 8$. I5, whereas the mean number of turns per intention decreases at $\mathrm{C}_{1} ; 8$. I 5 . None of these differences however are statistically significant. Table 2 provides, for each session, the number and proportion of intentions that found expression through each of the categories of behaviour described above, as well as the corresponding number of turns (intentions expressed by behaviours of categories ( 1 ), (3) and (4) comprise more turns than the others because of verticality).

The relative distribution of the categories suggests the existence of three main periods in the development from single to multiple-word speech.

\section{The First Period: the first manifestations of chaining and relatedness via repetition alone.}

This period may of course have started earlier than the first session analysed $\left(C_{1} ; 5.23\right)$ but it is still well represented in this session when $65 \%$ of the behaviours analysed are repetition of identical elements, vertical, horizontal, or both. The rest is divided about equally between chaining without relatedness and relatedness without chaining, of which $86 \%$ of the occurrences are based on the imitative reply. Only $6 \%$ of intentions (three occurrences) are expressed via behaviours of categories (4) and (5). The two occurrences in category (5) are: ebbé.pe ('baby.doll') while holding a baby doll in her hand and pip.káká ('weewee.poohpooh') while looking at her mother, which are of a rather special kind. 
FROM ONE WORD TO TWO WORDS

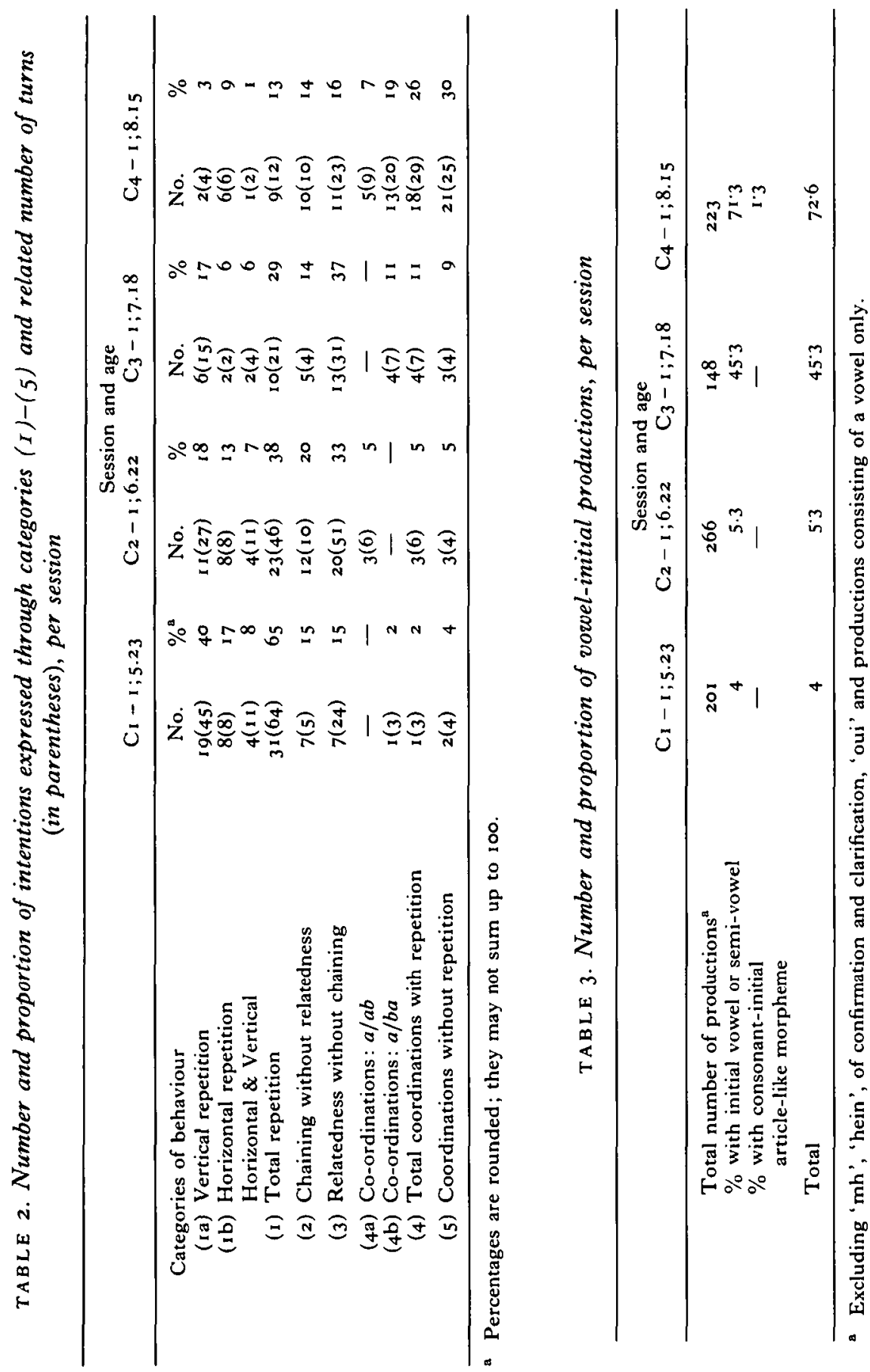




\section{The Second Period: chaining without relatedness on relatedness without chaining}

This period starts at $C_{1} ; 6.22$ and extends through $C_{I} ; 7.18$. In both sessions about half the intentions are expressed in this way with a notable difference however: whereas at $C_{1} ; 6.2285 \%$ of intentions expressed by category (3) (relatedness without chaining) are based on the imitative reply, only $30 \%$ of them are so based at $C_{1} ; 7.18$. Simple repetition alone diminishes gradually from $\mathrm{C}_{\mathrm{I}} ; \mathbf{6 . 2 2}$ onwards. Co-ordinations between chaining and relatedness are still rare. At $\mathrm{C}_{\mathrm{I}} ; \mathbf{6 . 2 2}$ they constitute $10 \%$ of intentions (six occurrences) of which half have the $a / a b$ repetition pattern and half are without repetition. At $\mathrm{C}_{1} ; 7.18$ they constitute $20 \%$ of intentions (seven occurrences) of which $57 \%$ present the $a / b a$ repetition pattern and the rest are without repetition.

\section{The Third Period: the co-ordination between chaining and relatedness}

$\mathrm{C}_{20}$; 5 illustrates this period particularly well. In this session we find a sudden increase in the behaviours showing co-ordination of chaining and relatedness (39 instances representing $56.5 \%$ of the behaviours in categories ( 1$)-(5)$, compared to the $20 \%$ at $\left.\mathrm{C}_{1} ; 7.18\right)$, divided about equally between coordinations with and without repetition. Of the co-ordinations with repetition, $72 \%$ ( 13 out of 18 instances) are of the $a / b a$ type. Fig. I illustrates well the progressive co-ordination between chaining and relatedness when the child says more than one word to express one intention. At $C_{1} ; 5.23$ and $\mathrm{C}_{1} ; \mathbf{6 . 2 2}$, when the child produces a chained utterance, most of the time the elements cannot be ascribed to one single intention; when she produces two words that relate to one single intention, most of the occurrences are not chained. At $\mathrm{C}_{1} ; 8$. I $_{5}$, on the contrary, most of the events in which two or more elements are uttered (within a turn and/or for one single intention) are expressed through the coordination of chaining and relatedness. $C_{1} ; 7.18$ is intermediate between them.

The session $C_{I} ; 7.18$ appears to present a turning point in this progress towards co-ordination. Compared to the earlier sessions, at $\mathrm{C}_{1} ; 7.18$ we find an increase in the number of words uttered with an initial vocalic sound [a],[æ],[e],[ə],[o]. As can be seen in Table 3 , at $C_{I} ; 6.22$ only about $5 \%$ of the words and word-like elements produced present an initial vowel: most of the time the child says word like bébé ('baby'), fa ('cat'), ko ('again'), mamã ('mommy'), pa ('no'), fõ ('bouchon' = 'cork'), pik ('sting'), etc. At C 1 ; 7.1 8 , $45 \%$ of the production presents a vocalic sound often marked by a glottal stop: ePbé, ofá, a?kó, a?má, orpá, e?fõ, æpik, e?pẽ ('pain' = 'bread'), ePtín

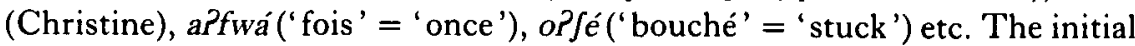
glottal stop occurs also in the production of lexical items where the vocalic sound is part of the word itself: arty' (from: 'voiture' = 'car') a?si(for 'assis' 


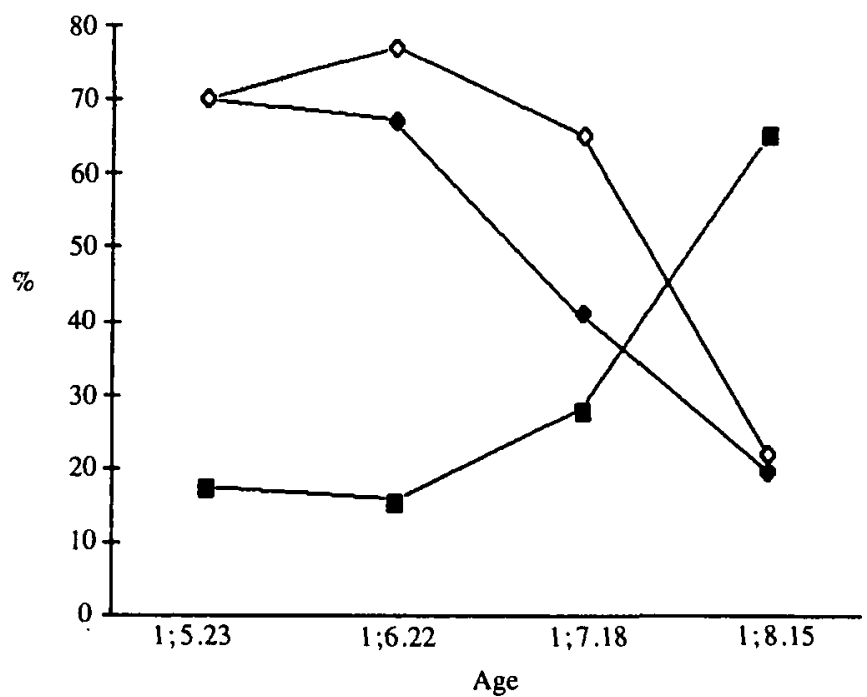

Fig. I. Co-ordination of chaining and relatedness over time. $\longrightarrow$, chaining: \% without relatedness; $\diamond-\diamond$, intentions with relatedness: \% without chaining $\square-$, events with $2(+)$ different elements: \% with chaining and relatedness

$=$ 'seated'). At $\mathrm{C}_{20}$; 15 the phenomenon is even more frequent since about $73 \%$ of the production consists of vowel-initial lexical items and some even show an article-like morpheme (lechien $=$ 'thedog'). The glottal stop has practically disappeared: agry' ('gru' = 'crane'), oli (from 'on lit' = 'let's read'), oppá (from 'veux pas' = 'don't want'), odó (from 'dodo'), abui ('bouche' = 'mouth').

As was noted by other authors (e.g. Bloom, 1970; Dore et al. 1976; Dolitsky, 1983), these vocalic additions do not seem to modify the meaning of the words nor increase their communicative value. Their appearance reflects the child's incipient concern with formal aspects of utterances based on her noticing certain regularities, like the fact that content words are frequently preceded by something which, in adult French, is a determiner, an auxiliary or a pronoun. Together with the productive use of the $a / b a$ pattern we find a parallel attention to the formal characteristics of words. Both of these phenomena occur in a more than sporadic way at $\mathrm{C}_{\mathrm{I}} ; 7.18$ just before the sizeable increase in two-word speech observed at $\mathrm{C}_{\mathrm{I}} ; 8.15$.

\section{DISCUSSION}

Interpretation of the developmental sequence reported hinges essentially on two points: (I) the co-ordination between chaining and relating, both of which apparently have their source in earlier behaviour, i.e. chaining as the 
temporal contiguity of simple repetition of one word and relating as an identity relation on the one hand, and as the relation between different words used to verbalize recurring intentions on the other; and (2) the importance of repetition as a psychological mechanism.

Dore et al. (1976) also proposed that early two-word combinations result from the co-ordination of previously acquired abilities which, in accord with the importance they attributed to the intonational contour, they proposed to be the coordination of 'conceptual relations with prosodic patterns' (p. 26). We propose a different kind of co-ordination, i.e. that between two basic characteristics of human language, chaining and relating. Chaining is the ability to utter more than one word in close temporal contiguity and relating is the ability to utter more than one word to express one single intention. Chaining, while not yet necessarily presenting prosodic unity, furthers the idea that utterances are characterized by a plurality of vocal elements produced in close proximity while relating furthers the idea that utterances contain different words that all relate to the same intention.

We agree with Bloom (1973) when she interprets the child's ability to produce more than one word, as in 'holistic successive single-word utterances' (which in our classification would belong to categories $(3),(4)$ or (5) depending on the temporal lag between the uttered words and on the dialogue structure), as a manifestation of the ability to hold in mind more than one aspect of a situation; but we would like to emphasize that though the ability to HOLD IN MIND more than one aspect of a situation is certainly a general cognitive acquisition, to be able to TALK about them in temporal contiguity, one AFTER the other, is an acquisition in language.

Chaining and relating are fundamental to multi-word utterances and their coordination is a development in language capacity. It enables the child to utter two words in temporal sequences which often express simultaneous aspects of a single intention. The temporal linearity of language can now also be used to express relations of meaning that do not unfold along the temporal dimension. This development does not as yet qualify as grammar but in our view constitutes a necessary condition for further linguistic progress. Having acquired the notion of relating by chaining, children are confronted with the fact that chaining implies an order in the production of words. They can thus proceed to the idea that this order is linked to relational meanings and, eventually, that contrasting word-orders can correspond to different meanings. We would like to propose that the co-ordination patterns encountered in the data presented here (classified in categories (4) and (5)) are the basis from which the various positional patterns described by Braine (1976) can be elaborated.

Similarly, we believe, this co-ordination opens the possibility for the child to begin to notice morphology. In a sense, the addition of grammatical morphemes to certain words, as imposed by languages such as French, is 
another type of chaining, and the appearance, during the third period, of vocalic elements at the beginning of words that were used earlier without these additions seems to confirm this supposition.

The importance of repetition as a psychological mechanisms for the emergence of two-word utterances is, in our opinion, twofold. In the first place, the simple repetition (often in close temporal contiguity) of the one word the child has uttered with a certain intention prefigures, at the singleword level, chaining and relating. Simple repetition of one word is still basically a typical single-word mode of functioning; nevertheless, it creates a new entity (more-than-one-word to express a single intention). In the second place, as we have already shown, repetition in the $a / a b$ and $a / b a$ patterns appears to provide a bridge towards the two-word constructions. These patterns appear to indicate that the child somehow becomes concerned with the relation between the words themselves, rather than the relation of each word to a single intention. In the pattern $a / a b$ the child repeats one word BEFORE uttering the second one. Repetition appears here to function as a means to gain time while searching for another word to utter, as a sort of temporizer or 'springboard' towards the next word, to take a term used by Elbers $(1982 ; 60)$ in her description of the relationship between repetitive babbling and first words. In the case of the $a / b a$ pattern the repeated word is uttered AFTER a second word has already been produced and thus cannot have the same temporizing, exploratory function. Why does the child again utter the initial word? We would like to suggest that here the child is starting to consider that two words may be needed for the production of utterances. If so, the $a / b a$ pattern would provide incipient evidence that children are acquiring knowledge about compositionality between words, although they would not yet know much about rules governing their combination. This interpretation is strengthened by the fact that the $a / b a$ pattern is the only repetition pattern observed at $C_{1} ; 7.18$, the session when we find the child's concern with the form of words, as evidenced by the sudden increase in vowel-initial lexical items. Thus repetition does not seem to be a trivial phenomenon in the acquisition process; rather it appears to play an important part for the child's understanding of how the linearity of human language functions.

Repetition furthermore seems to be an important facilitatory factor for prosodic integration at the level of speech production. The fluency of the articulatory plan which, following Branigan (1979), we feel to be dependent on a timing mechanism, would appear to be greatly facilitated when one of the words that will be uttered in combination is first produced and then repeated. Fluency of the articulatory plan does not necessarily imply the appearance of a single intonational contour, which is generally considered to be an indication of genuine two-word combinations in English. The distinction between stress-timed and syllable-timed languages (and various 
in-between types) is relevant here. French is certainly less stress-timed than English, though more so than Spanish. Moreover, at the level of the very first combinations, which is the object of our analysis, output fluency does not in our opinion imply that the child has elaborated positional patterns (Braine, I976) or structural rules more in general.

Repetition, especially in verbal interaction, can also be considered to be a factor that facilitates the child's progress from a different (and probably complementary) theoretical point of view. The construction of utterances in a dialogue implies complex processing of grammatical rules and lexical decisions. Repetition of either part of an utterance, or of the whole, with or without variations or expansions, and equally when adults repeat something uttered by children as when the children repeat themselves or adult utterances, reduces the demands on the child's processing capacities, as argued by Shatz (1978) and by Lieven (1984). The interactional aspect of repetition as it occurs in the dialogue, and of imitation, needs further analysis in order to determine whether their most important contribution is at the superficial level of production or at a deeper level as a catalyst in the acquisition of more fundamental notions (Sinclair, 1988).

Further speculation suggests a link between our view on the transition towards two-word utterances and what Kempen \& Hoenkamp (1987) have called Incremental Procedural Grammar. Essentially Kempen \& Hoenkamp propose that output fluency of utterances (in adults) is the result of three processes of speaking, i.e. conceptualizing, formulating and articulating, but not in serial temporal alignment. It is often assumed that first the conceptual content is specified, then the grammatical structure is built, and then this structure is realized phonetically. But according to Kempen \& Hoenkamp the three processes can run in parallel, 'conceptual fragments' being formulated as potential 'sentence fragments' while other conceptual fragments are still in the process of being built. Moreover, the order of the 'conceptual fragments' does not necessarily correspond to the order of the phonetically elaborated utterance fragments. It is possible to consider the first two-word utterances as the manifestation of the beginnings of a simultaneous or temporally overlapping processing mechanism. During the single-word period, the child directly passes from conceptual fragments to their articulatory production and the repetition patterns are an indication that there still is a need for this type of functioning. The advent of the $a / b a$ pattern appears to provide instances of an overlapping between conceptualizing and uttering, facilitated by repetition : a conceptual fragment can now be 'held' to take its place in an integrated utterance, if it has already been articulated on its own. At the same time, the appearance of vocalic additions to certain words seems to announce the beginnings of a grammatical process between conceptual constructions and utterance constructions.

Although clearly speculative, these hypotheses may help to clarify the 
intriguing question of the transition between the single-word period and the appearance of the first two-word combinations. At least, we hope to have shown the importance of repetition for 'breaking' the single-word functioning of the young child and for 'building up' new solutions at the level of multiple-word speech.

\section{REFERENCES}

Antinucci, F. \& Parisi, D. (1973). Early language acquisition: a model and some data. In C. A. Ferguson \& D. I. Slobin (eds). Studies of child language development. New York: Holt, Rinehart \& Winston.

Atkinson, M. (1979). Prerequisites for reference. In E. Ochs \& B. B. Schieffelin (eds), Developmental Pragmatics. New York: Academic Press.

- (1985). The status of children's single-word speech. In M. D. Barrett (ed.), Children's single-word speech. Chichester: Wiley.

Bloom, L. (1970). Language development: form and function in emerging grammars. Cambridge, MA.: M.I.T. Press.

- (1973). One word at a time. The Hague: Mouton.

Braine, M. D. S. (1963). The ontogeny of English phrase structure: the first phase. Language 39. 1-13.

- (1976). Children's first word combinations. Monographs of the Society for Research in Child Development 4I. No. 164.

Branigan, G. (1979). Some reasons why single-word utterances are not. Fournal of Child Language 6. $411-23$.

Brown, R. (1973). A first language: the early stages. Cambridge, MA: Harvard University Press.

Dolitsky, M. (1983). The birth of grammatical morphemes. Journal of Psycholinguistic Research 12. 353-60.

Dore, J., Franklin, M. B., Miller, R. \& Ramer, A. L. H. ( 1976). Transitional phenomena in early language acquisition. Fournal of Child Language 3. $13-28$.

Elbers, L. (1982). Operating principles in repetitive babbling: a cognitive continuity approach. Cognition $17.45-63$.

Greenfield, P. M. \& Smith, J. N. (1976). The structure of communication in early language development. New York: Academic Press.

Hockett, C. F. (1958). A course in modern linguistics. New York: Macmillan.

Kempen, G. \& Hoenkamp, E. ( 1987 ). An incremental procedural grammar for sentence formulation. Cognitive Science 11. $201-58$.

Lieven, E. V. M. (1984). Interactional style. and children's language learning. Topics in Language Disorders 4. 15-23.

Lyons, J. (1977). Semantics. Vol. I. Cambridge: C.U.P.

Martinet, A. (1949). La double articulation linguistique. Travaux du Cercle Linguistique de Copenhague 5. 30-7.

Miller, W. R. \& Ervin, S. (1964). The development of grammar in child language. In U. Bellugi \& R. Brown (eds), The acquisition of language. Monographs of the Society for Research in Child Development 29. No. 92.

Ochs, E., Schieffelin, B. B. \& Platt, M. L. (1979). Propositions across utterances and speakers. In E. Ochs \& B. B. Schieffelin (eds), Developmental Pragmatics. New York: Academic Press.

Saussure, F. de (1916). Cours de linguistique générale. Edition critique by Tullio de Mauro. Paris: Payot.

Schlesinger, I. M. (1974). Relational concepts underlying language. In R. L. Schiefelbusch \& L. Lloyd (eds), Language perspectives: acquisition, retardation and intervention. Baltimore: University Park Press.

Scollon, R. (1974). The child's language from one to two: the origins of construction. Unpublished doctoral dissertation, University of Hawaii, Honolulu. 


\section{CHILD LANGUAGE}

Scollon, R. (1979). A real early stage: an unzippered condensation of a dissertation on child language. In E. Ochs \& B. B. Schieffelin (eds), Developmental Pragmatics. New York: Academic Press.

Shatz, M. (1978). The relationship between cognitive processes and the development of communication skills. In C. B. Keasey (ed.), Nebraska Symposium on motivation. Lincoln: University of Nebraska Press.

Sinclair, H. (1988). Structures de l'intelligence et capacités communicatives. In C. Cornoldi \& R. Vianello (eds), Handicap, comunicazione e linguaggio. Bergamo: Edizioni Juvenilia.

Veneziano, E. ( 1988 ). Vocal-verbal interaction and the construction of early lexical knowledge. In M. Smith \& J. Locke (eds), The emergent lexicon: the child's development of a linguistic vocabulary. New York: Academic Press. 